\title{
Corrigendum to "Advanced Topics in Modeling, Bifurcation Analysis, and Control Theory of Complex Systems"
}

\author{
Olfa Boubaker $(\mathbb{D}),{ }^{1}$ Sajad Jafari $\left(\mathbb{D},{ }^{2}\right.$ Christos Volos $\mathbb{D},{ }^{3}$ Zeraoulia Elhadj, ${ }^{4}$ \\ Viet-Thanh Pham $(1),{ }^{5}$ and Jinde Cao ${ }^{6}{ }^{6}$ \\ ${ }^{1}$ University of Carthage, National Institute of Applied Sciences and Technology, Tunis, Tunisia \\ ${ }^{2}$ Amirkabir University of Technology, Tehran, Iran \\ ${ }^{3}$ University of Thessaloniki, Thessaloniki, Greece \\ ${ }^{4}$ University of Tébessa, Tébessa, Algeria \\ ${ }^{5}$ Hanoi University of Science and Technology, Hanoi, Vietnam \\ ${ }^{6}$ Southeast University, Nanjing, China \\ Correspondence should be addressed to Olfa Boubaker; olfa.boubaker@insat.rnu.tn \\ Received 9 July 2019; Accepted 11 July 2019; Published 24 July 2019
}

Copyright (C) 2019 Olfa Boubaker et al. This is an open access article distributed under the Creative Commons Attribution License, which permits unrestricted use, distribution, and reproduction in any medium, provided the original work is properly cited.

In the article titled "Advanced Topics in Modeling, Bifurcation Analysis, and Control Theory of Complex Systems" [1], there was an error in the first affiliation, where the name of the university was missing. The corrected affiliation is shown above.

\section{References}

[1] O. Boubaker, S. Jafari, C. Volos, Z. Elhadj, V.-T. Pham, and J. Cao, "Advanced topics in modeling, bifurcation analysis, and control theory of complex systems," Complexity, vol. 2018, Article ID 9417479, 3 pages, 2018. 


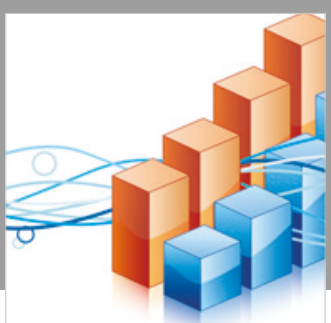

Advances in

Operations Research

\section{-n-m}
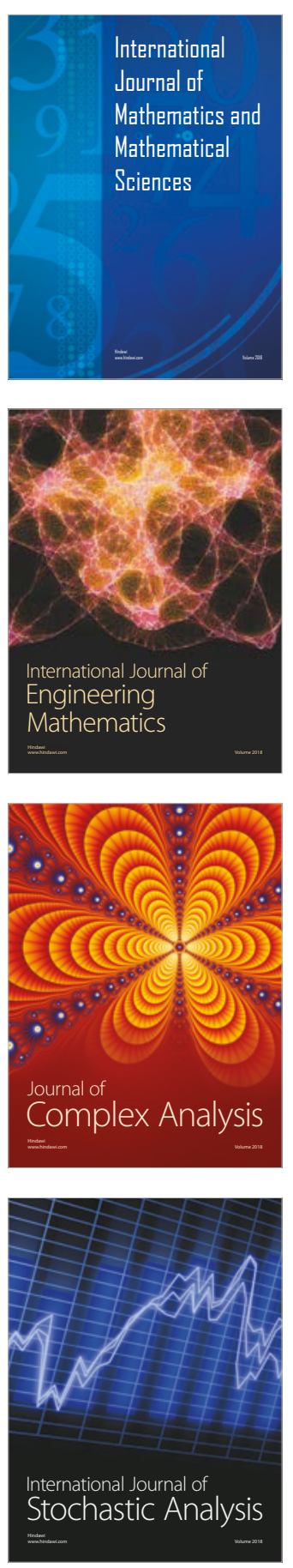
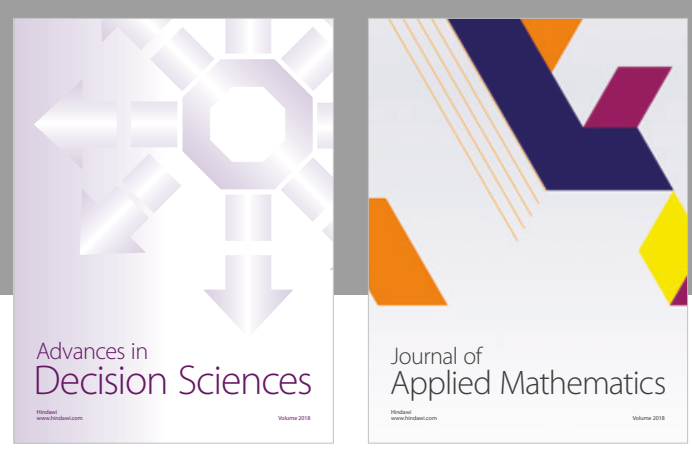

Journal of

Applied Mathematics
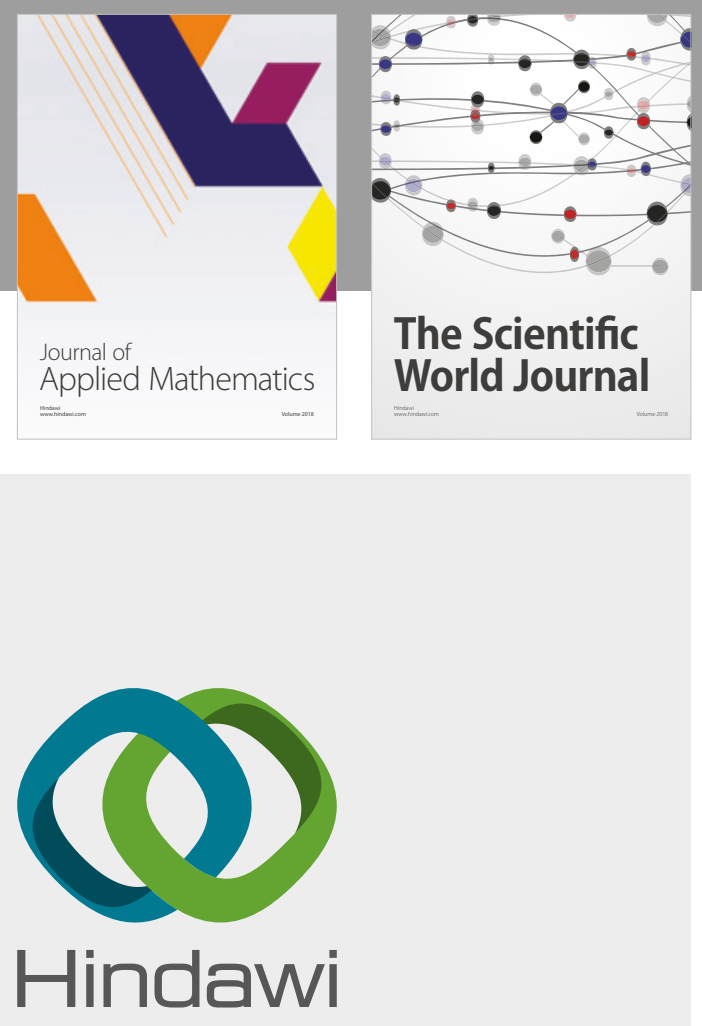

Submit your manuscripts at

www.hindawi.com

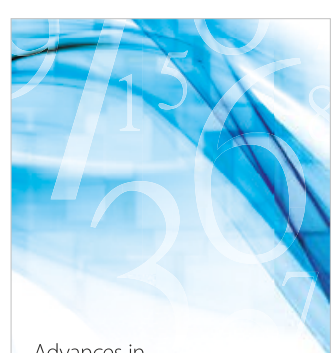

Advances in
Numerical Analysis
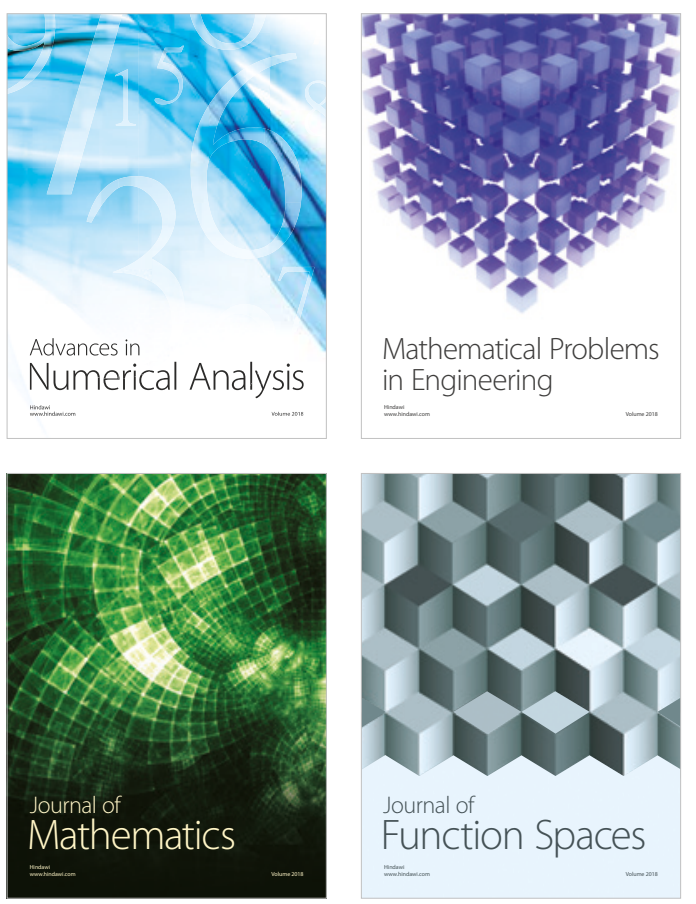

Mathematical Problems in Engineering

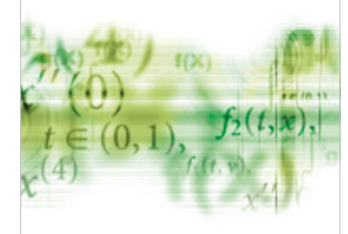

International Journal of

Differential Equations

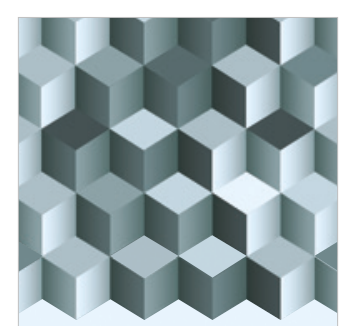

Journal of

Function Spaces
The Scientific

World Journal

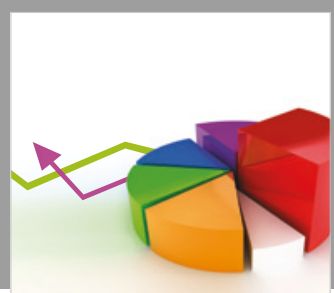

Journal of

Probability and Statistics
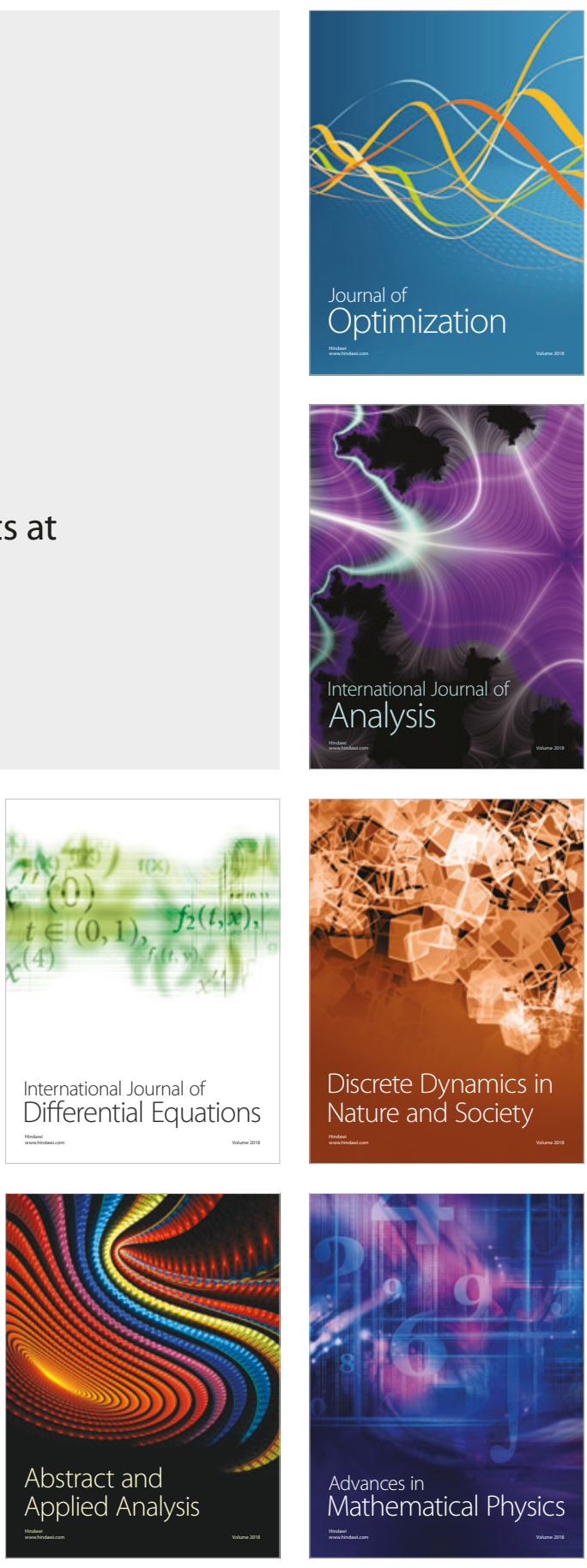